\title{
NB1, a New Neutrophil-Specific Antigen Involved in the Pathogenesis of Neonatal Neutropenia
}

\author{
Parviz Lalezari, Georgette B. Murphy, and Fred H. Allen, Jr. \\ From the Blood Bank, Department of Medicine, Montefiore Hospital and \\ Medical Center, New York 10467 and The New York Blood Center, \\ New York 10021
}

\begin{abstract}
A в S T RACT A new human antigen is reported which is present only on blood neutrophils. A neutrophil-specific antigen, designated NA1, has previously been identified in two unrelated families, and was shown to be involved in fetomaternal incompatibility and the development of isoimmune neonatal neutropenia in five newborns. In the present paper, a second antigen, designated $\mathrm{NB} 1$, is identified in four families with seven affected children. Antibodies that react with this second antigen are shown to produce selective agglutination of neutrophils but not other blood cells. They are neither absorbed by cells prepared from solid tissues nor by non-neutrophilic blood cells.

By family and population studies, NB is shown to be distinct from NA, representing an independent genetic locus. $68 \%$ of the New York population are homozygous for NB1, 29\% heterozygous, and 3\% negative. The NB locus is shown to be independent from those of HL-A and other known leukocyte antigens. No evidence for linkage between NA, NB, and red cell antigens was obtained.
\end{abstract}

\section{INTRODUCTION}

Neonatal neutropenia is a disorder of the newborn resulting from maternal isoimmunization by fetal neutrophils (1-3). Although identification of the immunological basis of this condition has had important clinical implications, characterization of the antibodies involved and the corresponding antigens has wider application. Since the antibody involved is neutrophil specific, an opportunity is provided to characterize an "organ-specific" antigen in a nucleated cell, a possibility not available with the previously described HL-A antibodies which appear to identify antigens widely distributed among various tissues (4). Moreover, although tissue-specific

Received for publication 23 October 1970 and in revised form 7 December 1970. heteroimmune sera have been produced in the past (5), these have not shown differentiation among different individuals of the same species (isospecificity). Antineutrophil antibody may provide a unique opportunity to identify and characterize neutrophil membrane components which may be only incidentally antigenic. Finally, the neutrophil-specific antigens provide a new genetic marker.

The present study reports a new neutrophil-specific antigen-antibody system, designated NB1 (6). As was the case with the first, now designated NA1, the antibody became evident in a woman whose newborns developed isoimmune neonatal neutropenia (INN). ${ }^{1}$ Retrospective studies on three additional families with similarly affected infants showed that the same NB1 antigen-antibody system had been involved.

\section{EXPERIMENTALS}

Subjects. The selective absence of blood neutrophils during the perinatal period was the common feature of all patients included in this study. In general, the profound neutropenia lasted from 3 wk to 3 months. Most of the newborns had transient infections, but in general they remained asymptomatic; there was one death from overwhelming infection at the age of 15 days. These families, in the order that the disease was diagnosed, are as follows:

(a) Ca. family, shown in Fig. $1 \mathrm{~A}$, was the subject of reports by Slobody, Abramson, and Loiseaux (7), Lehndorff (8), and Luhby and Slobody (9). Both newborns were affected.

(b) P. family, shown in Fig. $1 \mathrm{~B}$, was the subject of previous reports by Buckwold and Emson (10) and by Braun, Buckwold, Emson, and Russell (11). The mother had received a unit of blood from her husband following her second pregnancy, which terminated in a stillbirth. There were three documented affected newborns in this family but no laboratory data are available from the perinatal period of four other children.

(c) Ya. family. The only affected newborn, shown in Fig. $1 \mathrm{C}$, was reported by Rossi and Brandt (12).

\footnotetext{
${ }^{1}$ Abbreviations used in this paper: INN, isoimmune neonatal neutropenia.
} 

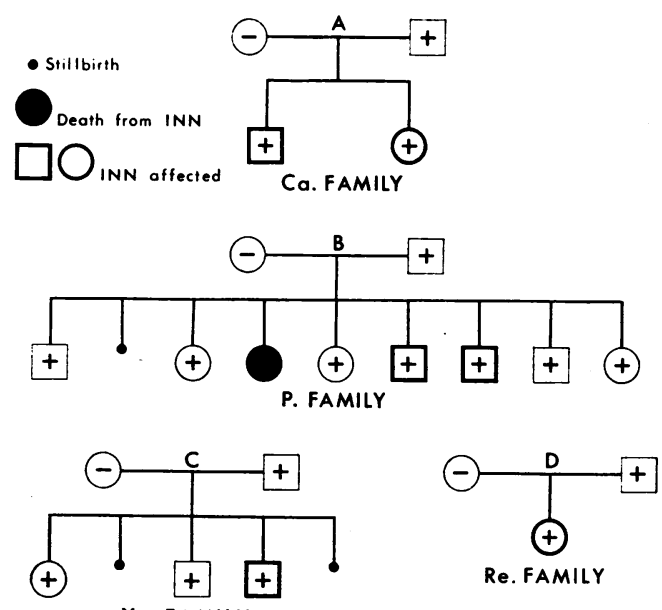

Ya. FAMILY

FIGURE 1 Four unrelated families with seven newborns affected with neonatal neutropenia. All fathers and children are $\mathrm{NB} 1+$ but all mothers are NB1 -

(d) Re. family. ${ }^{2}$ There was one affected child in this family, illustrated in Fig. $1 \mathrm{D}$.

Methods. The method employed for the detection of leukocyte agglutinins has been previously reported (3). Important features of this test system are the use of disodium ethylenediaminetetraacetate (EDTA) in the antigen-antibody incubation mixture, and a prolonged incubation time. EDTA has been shown to be required for the detection of certain types of leukocyte antibodies (4). All tests were performed using 12 consecutive two-fold dilutions of the test plasma in $0.9 \% \mathrm{NaCl}$; the same dilutions of plasma obtained from healthy donors were used as controls.

The morphological identity of the cells agglutinated by the antibody was determined by microscopic examination of incubation mixtures that had been dried on microscope slides and prepared by Wright's stain (3). Techniques for the preparation of various blood and tissue cells and their application in antibody absorption procedures were those previously reported (3). The lymphocytotoxicity test was performed according to the method of Mittal, Mickey, Singal, and Terasaki (13).

Methods for DEAE-cellulose column chromatography and 2-mercaptoethanol treatment of the antibody are described in an earlier report (3).

For antibody concentration, the method of $\mathrm{Na}_{2} \mathrm{So}_{4}$ precipitation described by Kekwick (14) was adapted. The precipitates were separated by centrifugation, dissolved in distilled water, and dialyzed overnight at $4^{\circ} \mathrm{C}$ against $0.9 \%$ $\mathrm{NaCl}$. More recently, antibody concentration was achieved by the use of polyacrylamide gel (Lyphogel, Gelman Instrument Company, Ann Arbor, Mich). Blood samples to be tested for antibody were anticoagulated by $1 / 100$ th volume of $10 \%$ EDTA. $8 \mathrm{ml}$ of plasma were incubated at room temperature for $4 \mathrm{hr}$ with $1 \mathrm{~g}$ of Lyphogel. The separated concentrates, which had a four- to fivefold increase in antibody titers, were stored at $-20^{\circ} \mathrm{C}$ until use. Prior to testing, debris was removed by centrifugation for $5 \mathrm{~min}$ at $\mathbf{5 0 0 0}$ $g$. Controls consisted of the concentrates prepared similarly from plasma of normal donors. In order to avoid nonspecific aggregation of leukocytes in high protein media,

${ }^{2}$ Raussen, A., and P. Lalezari. Manuscript in preparation. the length of incubation time of leukocytes with plasma concentrates was reduced to $3 \mathrm{hr}$.

\section{RESULTS}

$P$. family. The plasma obtained from Mrs. Isobel P. had strong leukocyte agglutinating activity when tested with cells obtained from her husband and from all of her seven surviving children, but it failed to react with her own cells (Fig. 1 B). The agglutinin had a titer varying from 64 to 1024 when tested with different donor leukocytes. Agglutination required at least 2 $\mathrm{hr}$ of incubation at $37^{\circ} \mathrm{C}$, but maximum agglutination did not occur until $8 \mathrm{hr}$. The plasma reactivity was not destroyed by heating for $30 \mathrm{~min}$ at $56^{\circ} \mathrm{C}$, or by 2 -mercaptoethanol treatment. As shown in Fig. 2, the activity was primarily in the $7 \mathrm{~S}$ globulin fractions when subjected to DEAE-cellulose column chromatography. Various blood samples collected from Mrs. P. at different intervals in the past $6 \mathrm{yr}$, and as late as $6 \mathrm{yr}$ after her last pregnancy, have shown unchanged antibody activity. In the present communication, donors whose leukocytes were agglutinated by Mrs. P's plasma were considered to be NB1 + and those whose leukocytes were not agglutinated were considered to be NB1 -.

Cell specificity. Blood neutrophils were the only cells agglutinated by the antibody in Mrs. P.'s plasma. This was demonstrated on stained slides prepared from the agglutinated leukocytes of five different donors who had a high ratio of eosinophils, and five adult donors with a high ratio of lymphocytes. In all these preparations, the cells participating in the aggregates were identified as polymorphonuclear cells, while all other cells remained free. Similar results were obtained with blood samples

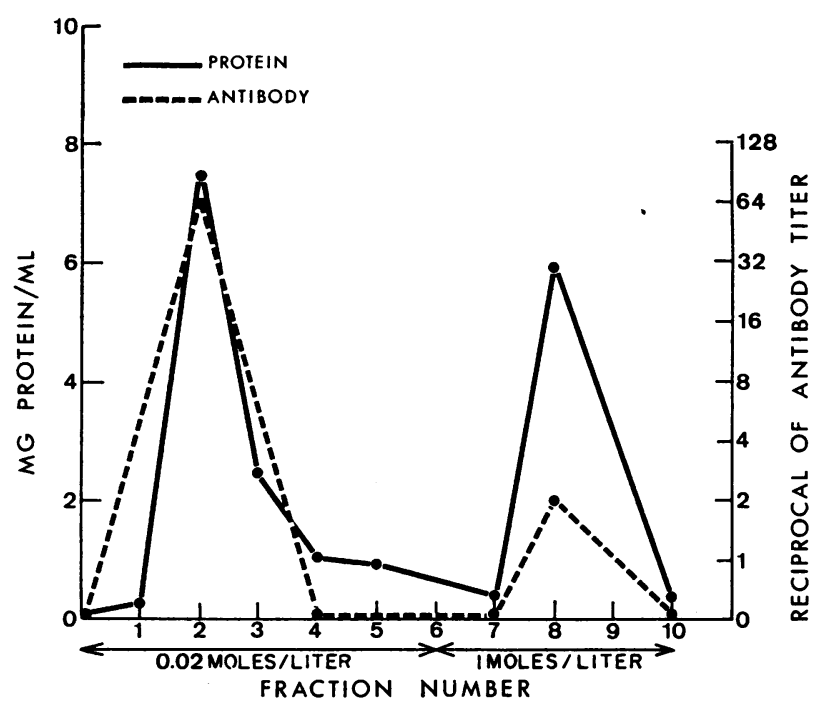

FIGURE 2 DEAE-cellulose column chromatography on serum of Mrs. P.

NB1, a New Neutrophil-Specific Antigen 


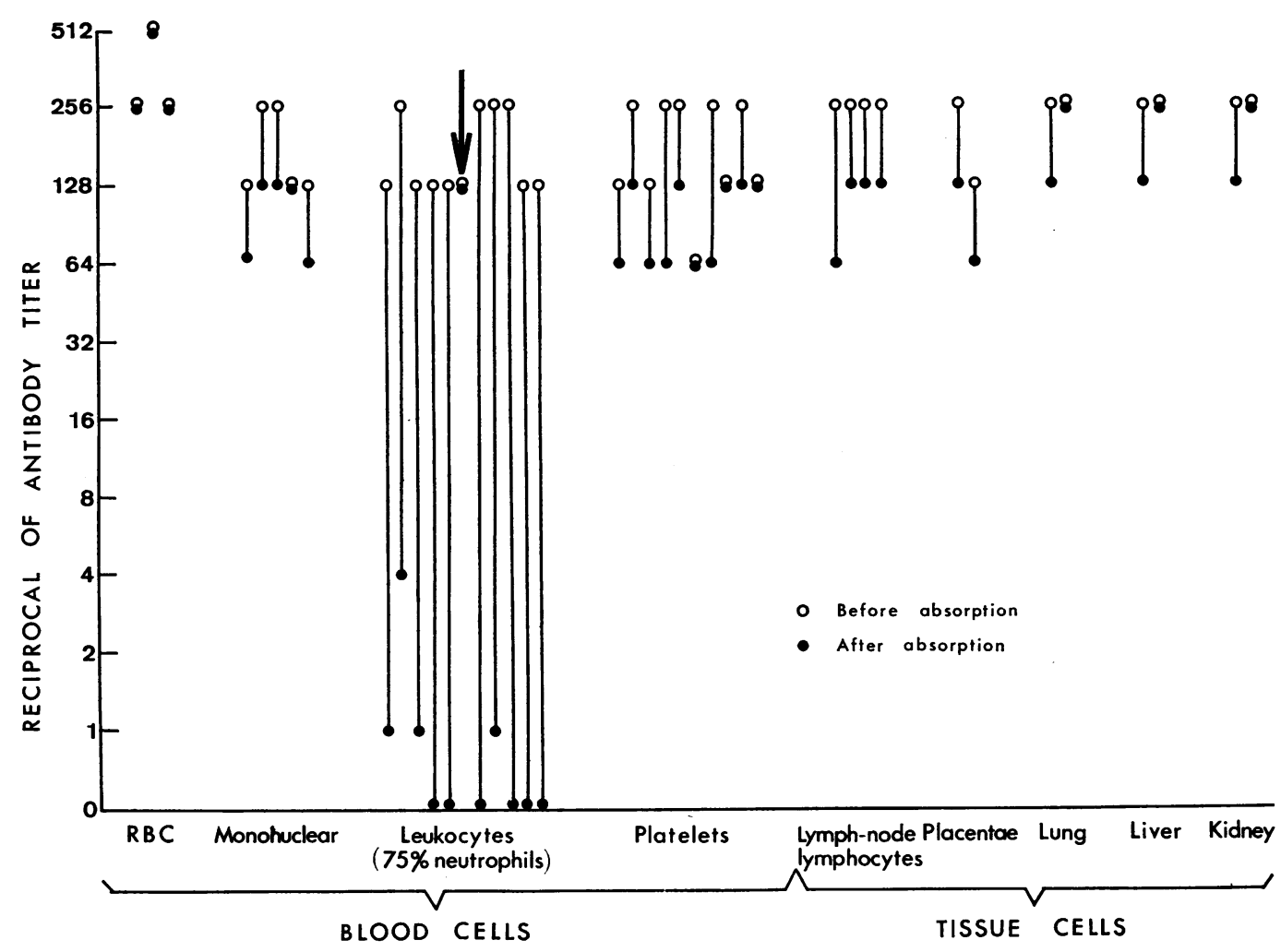

Figure 3 Absorption of Mrs. P. plasma by blood neutrophils; other blood or solid tissue cells do not absorb the antibody. The arrow indicates the results obtained by the use of a NB1 - leukocyte sample.

collected from five hematologically normal infants. These provided a convenient source of leukocyte preparations with a high ratio of normal lymphocytes. This agglutination pattern was in contrast with the pattern produced by "Ke" (15) antibody, which has been shown to react with an antigen having a wide tissue distribution.

Neutrophil specificity was further confirmed by antibody absorption experiments. Fig. 3 shows the results of absorption by various cell types. In these studies, Mrs. P.'s plasma was incubated with red cells, peripheral blood mononuclear cells (containing about $50 \%$ monocytes, $50 \%$ lymphocytes), platelets, lymph-node lymphocytes, or placental, lung, liver, or kidney cells obtained from NB1 + donors. Similarly, absorption was performed with "leukocyte" preparations which averaged about $75 \%$ neutrophils. In Fig. 3 are shown the results of titration of Mrs. P.'s plasma, before and after absorption, against each donor's own leukocytes. In experiments in which absorption was performed with lung, liver, and kidney cells, titrations were performed against leukocytes from $\mathrm{NB1}+$ donors other than the tissue donors. As shown in Fig. 3, leukocytes from an NB1 donor did not absorb the antibody, and no cell type other than those primarily composed of $\mathrm{NB} 1+$ neutrophils absorbed the antibody.

Antigen specificity. To determine whether Mrs. P.'s antibody detected a single antigen (or single antigenic complex), the antibody was first incubated with the peripheral blood leukocytes of 17 different donors. The absorbed plasmas were separated and were then titrated against each donor's own leukocytes. A significant antibody absorption was achieved in all instances; i.e., at least a 64-fold reduction in the antibody titer was achieved. These absorbed plasmas were then titrated against leukocytes of several NB1 + donors, to a total of 120 tests. As is indicated in Table I, the absorbed plasma failed to indicate the presence of antibody activity remaining after absorption by NB1 + leukocytes. These results suggested that the antibody in Mrs. P.'s plasma probably interacted with a single antigen.

Antigen frequency. The antigen detected in Mrs. P.'s plasma appears to have a high frequency: the leukocytes of all but 6 of 200 random Caucasian donors reacted. This corresponds to a gene frequency of 0.83 for NB1 and 0.17 for its allelic gene(s). Thus, $68.3 \%$ of population are expected to be homozygous, $28.7 \%$ heterozy- 
gous. Among 96 leukocyte samples tested during the Third International Histocompatibility Testing Workshop in Torino, Italy (6), 7 were negative, but 3 of these were from members of the same family.

NB1 antigen in other families with INN. Following characterization of the antibody in Mrs. P.'s plasma, it was of particular interest to determine whether the same antigen could be implicated in other reported cases of INN. For this study, members of three additional families (Ca., Ya., and Re.) in which cases of INN had been observed, were reevaluated.

Plasma from Mrs. Ca., which was collected 13 yr after her last pregnancy, contained an isoantibody that reacted weakly with her husband's leukocytes and with the leukocytes prepared from one of her two children. Leukocytes from the other affected child did not react, but this child's leukocytes were not tested with the concentrated plasma. The antibody did not react with the mother's own cells even when concentrated, but did react with the leukocytes of $25(38 \%)$ of 68 unrelated blood donors, with titers ranging from 1 to 8 . A sample collected $19 \mathrm{yr}$ after her last pregnancy failed to produce leukocyte agglutination even after fivefold concentration.

Plasma from Mrs. Ya., collected 2 yr after her last pregnancy, contained an antileukocyte antibody that reacted weakly with her husband's leukocytes and with those of two of her three children, but not with her own cells. It reacted with 17 of 48 random specimens with titers ranging from 1 to 4 . A new blood sample collected $7 \mathrm{yr}$ after her last pregnancy contained an antibody that could be detected only after plasma had been concentrated fivefold.

In the case of Re. family, a maternal isoantibody was found which reacted weakly with paternal leukocytes and those of baby Re., after recovery from INN. Among 65 unrelated donors, the neutrophils of 21 reacted, but none with a titer exceeding 8 .

As in the case of Mrs. P., neutrophil specificity of the antibodies was established in the other three mothers by the demonstration that they did not produce mixed-cell agglutination when tested with cell preparations containing high ratios of eosinophils or lymphocytes: agglutinated cells were exclusively neutrophils. The antibody was not absorbed by platelets or lymphocytes that had been prepared from the respective fathers or from unrelated positive donors, but could be removed completely by leukocyte preparations composed mainly of neutrophils. No cytotoxicity could be shown by these four sera, or by their concentrates, against lymphocytes of five NB1 + donors tested.

All members of these families were tested against the most potent antibody of the four, that of Mrs. P. As shown in Fig. 1, leukocytes prepared from Mrs. Ca., Mrs. Ya., and Mrs. Re. did not react with this antibody
TABLE I

Cross-Absorption Studies with Leukocytes

\begin{tabular}{|c|c|}
\hline $\begin{array}{l}\text { Absorbing } \\
\text { leukocytes }\end{array}$ & $\begin{array}{l}\text { Number of tests } \\
\text { indicating a re- } \\
\text { sidual antibody } \\
\text { in the absorbed } \\
\text { plasma }\end{array}$ \\
\hline $\begin{array}{r}17 \text { NB1 + } \\
1 \text { NB1 - }\end{array}$ & $\begin{array}{c}0 / 120 \\
10 / 10\end{array}$ \\
\hline
\end{tabular}

but leukocytes from all four husbands and all of the children reacted strongly, suggested that the four antibodies had the same specificity, and differed only in concentration. This was confirmed by testing the concentrates against leukocytes of five different $\mathrm{NB} 1+$ and five NB1 - donors. These concentrates, prepared from the plasmas of Mrs. Ca., Mrs. Ya., and Mrs. Re., produced reaction patterns identical to that of Mrs. P.'s plasma.

Comparison of NB1 with other leukocyte antigens. Table II shows the results of neutrophil typing of six mothers who were the sources of the antibodies used to identify NA1 and NB1 antigens. Both mothers who developed anti-NA1 were $\mathrm{NB1}+$, and of four mothers who produced anti-NB1, two were $\mathrm{NA1}+$, indicating nonidentity of the two antigens. The results of simultaneous typing of 102 unrelated New York donors for both NA1 and NB1 are shown in Table III, and indicate no relation between the two antigens.

Fig. 4 shows the results of leukocyte and red cell typings of family $\mathrm{Ch}$. (Torino 136 ), which provides substantial information on the linkage relationships of NA1 and NB1. The NA locus shows recombinations with NB, HL-A, and 9*. The NB locus shows recombinations with $\mathrm{HL}-\mathrm{A}$ and $\mathrm{ABO}$. There were no recombinations between NA and ABO in this family, but they have been observed in other families.

TABLE II

Nonidentity of NA1 and NB1 as Shown by Neutrophil Typing of NA1 and NB1 Antibody Producers

\begin{tabular}{lcc}
\hline & $\begin{array}{c}\text { Anti-NA1 } \\
\text { (DeR.) }\end{array}$ & $\begin{array}{c}\text { Anti-NB1 } \\
(\text { P.) }\end{array}$ \\
\hline Anti-NA1 producers & & \\
Mrs. DeR. & - & + \\
Mrs. St. & - & + \\
Anti-NB1 producers & & \\
Mrs. P. & + & - \\
Mrs. Ca. & - & - \\
Mrs. Re. & + & - \\
Mrs. Ya. & - & - \\
\hline
\end{tabular}

NB1, a New Neutrophil-Specific Antigen 
TABLE III

Simultaneous Typing for NA1 and NB1 of 102 Unrelated Leukocyte Donors

\begin{tabular}{|c|c|c|c|}
\hline \multicolumn{4}{|c|}{ NB1 } \\
\hline & + & - & Totals \\
\hline+ & 65 & 3 & 68 \\
\hline NA1 & & & \\
\hline- & 30 & 4 & 34 \\
\hline Total & 95 & 7 & 102 \\
\hline
\end{tabular}

$\mathrm{X}^{2}=1.92, P=0.17$

Table IV gives the lod scores at 10 values of $\theta$ for those comparisons with NA1 and NB1 that were informative in eight of the Torino families tested at the histocompatibility workshop in Torino, 1967, and reported in reference 6 . Results for $5^{\mathbf{a}}, 5^{\mathrm{b}}$, and $9^{\mathbf{a}}$ were those obtained by van Rood (6). HL-A typings were taken from the data of Ceppellini (6). Red cell typings were done at The New York Blood Center, and have not been reported previously.

"Lod scores" are figures that give a measurement of the likelihood of linkage. The mathematical statement is:

$$
\text { lod score }+\log _{10} P\left(\theta_{1}=\theta\right) / P\left(\theta=\frac{1}{2}\right) \text {. }
$$

The numerator in this statement is the probability that the assumed recombination frequency $\left(\theta_{1}\right)$ is the actual recombination frequency $(\theta)$. The denominator is the probability that the actual recombination frequency is $\frac{1}{2}$ (free recombination). The values given in the table are the sums of the lod scores for the eight informative families. A lod score of +3 or higher is considered to be strong evidence of linkage. A lod score of -2 or smaller indicates that linkage is ruled out at recombination frequencies less than the value given in the heading. For example, for the NA1 and Rh loci, linkage as close as two crossover units (2\% recombinations) is ruled out. Lod scores between +3 and -2 are considered to be indecisive. The various values of $\theta$ shown in the table are the assumed values for which the calculations were made. The first value of $\theta_{1}$ is not actually 0 , but is a very small number, less than 0.000005 . When asterisks are shown in the first column, instead of a lod score, the value was less than -100 (negative score in excess of 100).

The NA locus appears to be independent of the $\mathrm{ABO}$, MN, Rh, Kidd, HL-A, 9, and NB loci. The NB locus appears also to be independent of HL-A and 9. Very close linkage is ruled out for NA/ABO, NA/Rh, NA/ HL-A, and NA/NB.

\footnotetext{
${ }^{8}$ The linkage programs for the IBM Model 1130 Computer at The New York Blood Center were prepared by Dr. John H. Edwards of Birmingham, England, and Dr. Catherine Falk of the New York Blood Center, with the assistance of Mr. Richard Levine of The New York Blood Center.
}

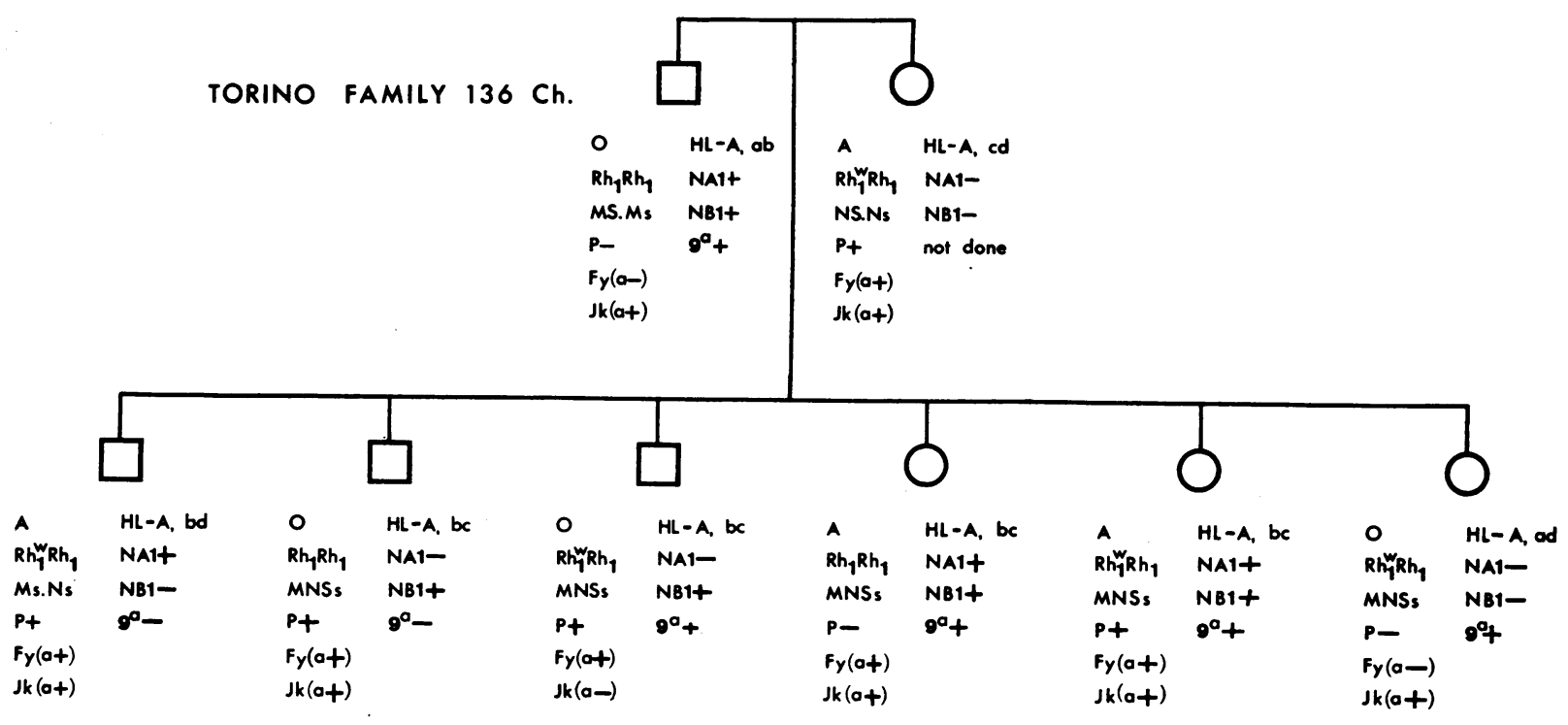

All are $k-k+K p(a-b+)$, Lu(a-), $5(a-b+)$.

FIgure 4 Red cell and leukocyte typing on a Torino family. The NA locus shows recombinations with $\mathrm{NB}, \mathrm{HL}-\mathrm{A}$, and $9^{*}$. The $\mathrm{NB}$ locus shows recombinations with HL-A and ABO. $a, b, c$, and $d$ are assigned to represent four parental HL-A chromosomes. 
TABLE IV

Lod Scores for Linkage Comparisons of the NA and NB Loci to Each Other and to Various Other Markers at 10 Values of $\theta$ (Torino Families)

\begin{tabular}{lrrrrrrrrrr}
\hline & \multicolumn{1}{c}{0.000} & \multicolumn{1}{c}{0.020} & \multicolumn{1}{c}{0.040} & \multicolumn{1}{c}{0.060} & \multicolumn{1}{c}{0.080} & \multicolumn{1}{c}{0.100} & 0.300 & 0.400 & 0.450 & 0.500 \\
\hline NA1/ABO & $* * * * * * *$ & -3.363 & -2.481 & -1.975 & -1.623 & -1.357 & -0.231 & -0.054 & -0.013 & 0.000 \\
NA1/MN & -10.413 & 0.216 & 0.449 & 0.557 & 0.614 & 0.643 & 0.392 & 0.139 & 0.039 & 0.000 \\
NA1/P & -0.053 & -0.049 & -0.045 & -0.041 & -0.037 & -0.034 & -0.008 & -0.002 & -0.000 & 0.000 \\
NA1/Rh & -24.051 & -2.067 & -1.483 & -1.151 & -0.924 & -0.754 & -0.104 & -0.022 & -0.005 & 0.000 \\
NA1/LU & -0.074 & -0.074 & -0.072 & -0.070 & -0.067 & -0.064 & -0.020 & -0.005 & -0.001 & 0.000 \\
NA1/FY & 0.032 & 0.029 & 0.027 & 0.025 & 0.023 & 0.020 & 0.005 & 0.001 & 0.000 & 0.000 \\
NA1/JK & -11.656 & -0.691 & -0.425 & -0.284 & -0.194 & -0.132 & 0.016 & 0.006 & 0.001 & 0.000 \\
NA1/HL-A & $* * * * * * *$ & -5.312 & -3.857 & -3.030 & -2.461 & -2.034 & -0.315 & -0.071 & -0.017 & 0.000 \\
NA1/5 & -0.177 & -0.161 & -0.147 & -0.133 & -0.120 & -0.108 & -0.025 & -0.006 & -0.001 & 0.000 \\
NA1/9 & -11.460 & -1.473 & -1.161 & -0.972 & -0.834 & -0.723 & -0.149 & -0.036 & -0.008 & 0.000 \\
NA1/NB1 & $* * * * * *$ & -3.329 & -2.450 & -1.946 & -1.598 & -1.334 & -0.226 & -0.052 & -0.013 & 0.000 \\
& & & & & & & & & & \\
NB1/ABO & -0.413 & -0.367 & -0.327 & -0.290 & -0.258 & -0.229 & -0.049 & -0.012 & --0.003 & 0.000 \\
NB1/MN & 0.524 & 0.495 & 0.466 & 0.437 & 0.408 & 0.379 & 0.116 & 0.031 & 0.007 & 0.000 \\
NB1/P & -0.025 & -0.022 & -0.019 & -0.016 & -0.014 & -0.012 & -0.001 & -0.000 & -0.000 & 0.000 \\
NB1/Rh & -0.446 & -0.396 & -0.352 & -0.312 & -0.277 & -0.245 & -0.052 & -0.012 & -0.003 & 0.000 \\
NB1/LU & -0.005 & -0.005 & -0.005 & -0.004 & -0.004 & -0.003 & -0.001 & -0.000 & -0.000 & 0.000 \\
NB1/FY & -0.402 & -0.357 & -0.317 & -0.282 & -0.250 & -0.222 & -0.048 & -0.011 & -0.002 & 0.000 \\
NB1/JK & -0.301 & -0.273 & -0.247 & -0.223 & -0.200 & -0.179 & -0.041 & -0.010 & -0.002 & 0.000 \\
& & & & & & & & & \\
NB1/HL-A & -21.640 & -1.471 & -0.900 & -0.584 & -0.374 & -0.224 & 0.143 & 0.058 & 0.016 & 0.000 \\
NB1/5 & -0.008 & -0.008 & -0.007 & -0.006 & -0.006 & -0.005 & -0.001 & -0.000 & -0.000 & 0.000 \\
NB1/9 & -11.392 & -1.335 & -1.008 & -0.810 & -0.669 & -0.560 & -0.090 & -0.020 & -0.005 & 0.000 \\
\hline
\end{tabular}

\section{DISCUSSION}

INN, a disorder analogous to erythroblastosis fetalis, is characterized by a selective and transient absence of segmented neutrophilic leukocytes in the blood and the bone marrow of affected newborns. This disease is caused by maternal isoantibodies that react only with blood neutrophils. These antibodies cross the placenta, and in the newborn cause destruction of neutrophils; other blood elements are not affected. The first maternal isoantibody shown to be responsible for INN was identified in family DeR. in 1959 (1-3). Subsequently, this antibody was shown to be neutrophil specific, detecting a single antigen initially called DeR. It was also shown to be involved in the development of INN in two unrelated families (3). Recently in a new case of INN in a Dutch family, the same NA1 specificity was implicated." Preliminary results from the study of a new patient born in Hawaii indicate the presence of maternal antibody directed against an allele to the NA1 antigen.

In 1960, Braun et al. (11) found an antileukocyte antibody in the blood of Mrs. Isobel P. who had three newborns affected with INN. The present report is

\footnotetext{
data.
}

concerned with the immunological characterization of this antibody.

The antigen NB1 is the second neutrophil-specific antigen described in man. Similar immunological properties and clinical implications found for both NA1 and NB1 establish the existence of neutrophil-specific antigens and confirm their clinical and biological significance. The present antigen is identified by neutrophil agglutinins present in the plasma of four unrelated mothers who had a total of seven newborns affected with isoimmune neonatal neutropenia. It is of particular interest that in two of these families, similar to the family reported earlier (1) the first born children were affected. In all instances, an isoagglutinin was demonstrated in the maternal blood that reacted with the paternal leukocytes and those of the children. The results of these tests, however, were not in complete agreement with those reported by the previous investigators who originally studied these same families. In the case reported by Luhby and Slobody (9), inability to demonstrate the antibody may have been due to its weak reactivity. Braun et al. (11) reported that the heated serum from Mrs. Isobel P. agglutinated leukocytes of her husband, those of the affected children, and three of six unrelated donors, but no reaction occurred with the leukocytes of unaffected children. Re- 
peating these tests in 1965 and again in 1966, positive reactions were obtained in this laboratory with the leukocytes obtained from all the children regardless of their past clinical history. Although the plasmas used in these latter experiments were collected 5 and $6 \mathrm{yr}$ later than those sera originally used, the difference in the frequency of the positive results can be explained on the basis of the difference in the sensitivity of the techniques employed. The neutrophil specificity of the antigen detected by these antibodies was established both by direct agglutination and by absorption experiments.

Failure of the lymphocytes and eosinophils to participate in antibody-induced neutrophil aggregates may indicate the absence of appropriate receptor sites for the specific antibody on these cells. Restriction of the antigen to neutrophils is further supported by the finding that antineutrophil agglutinins were absorbed only by neutrophil-rich preparations. Failure to elicit any lymphocytotoxicity by these sera, even after concentration, adds additional support to this conclusion. It is well known, however, that leukocyte antigen-antibody reactions may occur without demonstrable cytotoxicity (4). Indeed, none of neutrophil-specific antibodies heretofore studied has demonstrated cytotoxicity against neutrophils or lymphocytes. The possibility that NB1 may be present in other cells but not detected with the techniques employed has not been ruled out.

The absorption data shown in Table I indicate that the same antigen is present on all leukocytes used for absorption. The possibility that the plasma of Mrs. P. detects extra antigens not recognized by the sample size used in these experiments has not been ruled out. Such a possibility would be related to the frequency of these hypothetical extra antigens. The absorption data in Table I do not support the presence of an extra antigen with frequency of 50\% $(P<0.001)$. Additional studies are needed to rule out the presence of antigens of extreme low and high frequencies. Although "cross-absorptions" were employed only with Mrs. P. plasma, identical specificity for the antigen identified by all four plasmas or their concentrates was established by their identical reactions. These results are also consistent with the postulate that all the antisera were monospecific and detected a single antigen. It is of particular interest that this identity could not have been established unless the experiments with antibody concentrates were performed. Data obtained by the use of unconcentrated plasmas could have been interpreted as "partial identity" or existence of two or three antigens "included" in the main antigen detected by the strongest antibody. Additional evidence for the identity of these four antibodies is the finding that in all cases the maternal leukocytes produced a negative reaction when tested with plasma of Mrs. P. or plasma concentrates prepared from the other three mothers. This is particularly significant when the low (3\%) incidence of negative reactions in the general population is considered. The antigen identified by these plasmas fulfills the criteria for being genetically determined, and is inherited as a mendelian dominant characteristic, as indicated from family studies described in Fig. 1. This antigen segregates independently from NA1, and computer analysis of the Torino data fails to indicate linkage with other antigenic systems studied.

Neutrophil antigens appear to be highly polymorphic. In addition to NA1 and NB1, a third antigen has recently been identified in a family with a newborn affected with INN (16), and another antigen which appears to be an allele to NA1 has been recognized. ${ }^{5}$ Thus, in nine such families, four different antigens have been identified. $9^{\mathrm{a}}$ of van Rood may also be neutrophil specific ${ }^{\circ}$ and may represent another independent system.

The discovery of these specificities and the possibility of finding newer antigens creates a need for an appropriate nomenclature. In the system employed here the first letter $\mathrm{N}$ signifies neutrophil specificity, this being followed by single letters of the alphabet which represent different loci, i.e., NA, NB, etc. The Arabic numbers that follow these two letters would represent different alleles, NA1, NA2, etc. This proposed nomenclature has been used in the international workshops on histocompatibility.

Neutrophil isoantigens represent a high degree of polymorphism in a specialized nucleated cell. They also represent a "tissue-specific" antigen which can be detected by an isoantibody. Although the function of these neutrophil antigens remains to be studied, the development of neonatal neutrophenia in association with circulating antibodies indicates that these immunological reactions are responsible for the ultimate destruction of incompatible cells. This implies that the fate of neutrophils in bone marrow transplantation may similarly be influenced by neutrophil incompatibility. Since the existence of neutrophil-specific isoantigens is now established, the possibility exists that a similar antigenic characterization can be achieved for other tissues with corresponding organs and individual specificities. For this purpose, antibody preparation by a different isoimmunization method would be required.

\section{ACKNOWLEDGMENTS}

We wish to thank all the families subjected to this study for their continuous cooperation, and Dr. A. Leonard Luhby, Dr. Harry E. Emson, Dr. Ira K. Brandt, and Dr. Aaron R. Raussen for their permission to study these patients. We are also grateful to Miss Dorothy M. Couig and Dr. Theodore $\mathrm{H}$. Spaet for their assistance in preparation of this manuscript.

${ }^{5}$ Lalezari, P., and L. A. Boxer. Manuscript in preparation.

'van Rood, J. J. Personal communication. 
Dr. Lalezari was supported by United States Public Health Service Grant HE-10036-05 and National Institutes of Health Contract 29-6071. Dr. Allen was supported by United States Public Health Service Grants HE-08630 and HE-09011, and by grants from the Fay Hunter Estates and the Irwin Strasburger Memorial Medical Foundation.

\section{REFERENCES}

1. Lalezari, P., M. Nussbaum, S. Gelman, and T. H. Spaet. 1959. Neonatal neutropenia due to maternal isoimmunization. Clin. Res. 7: 13.

2. Lalezari, P., M. Nussbaum, S. Gelman, and T. H. Spaet. 1960. Neonatal neutropenia due to maternal isoimmunization. Blood J. Hematol. 15: 236.

3. Lalezari, P., and G. E. Bernard. 1966. An isologous antigen-antibody reaction with human neutrophiles, related to neonatal neutropenia. J. Clin. Invest. 45: 1741.

4. Walford, R. L. 1969. The isoantigenic systems of human leukocytes: medical and biological significance. Ser. Haematol. 2: 2 .

5. Milgrom, F. 1966. Tissue specific antigens and isoantigens. Ann. N. Y. Acad. Sci. 129: 767.

6. Curtoni, E, S., P. L. Mattiuz, and R. M. Tosi. 1967. Workshop Data in Histocompatibility Testing 1967. Munksgaard, Copenhagen. 435.

7. Slobody, L. B., H. Abramson, and L. S. Loizeaux, Jr. 1950. Agranulocytosis of the newborn infant. J. Amer. Med. Ass. 142: 25.
8. Lehndorff, H. von. 1951. Transitorische Granulocytopenie Beim Neugeborenen. Helv. Paediat. Acta. 6: 173.

9. Luhby, A. L., and L. B. Slobody. 1956. Transient neonatal agranulocytosis in two siblings. Transplacental isoimmunization to a leukocyte factor? Amer. J. Dis. Child. 92 : 496.

10. Buckwold, A. E., and H. E. Emson. 1959. Acute neonatal neutropenia in siblings. Can. Med. Ass. J. 80: 116.

11. Braun, E. H., A. E. Buckwold, H. E. Emson, and A. V. Russell. 1960. Familial neonatal neutropenia with maternal leukocyte antibodies. Blood J. Hematol. 16: 1745.

12. Rossi, J. P., and I. K. Brandt. 1960. Transient granulocytopenia of the newborn associated with sepsis due to Shigella alkalescens and maternal leukocyte agglutinins. J. Pediat. 56: 639.

13. Mittal, K. K., M. R. Mickey, D. P. Singal, and P. I. Terasaki. 1968. Serotyping for homotransplantation. XVIII. Refinement of microdroplet lymphocyte cytotoxicity text. Transplantation. 6: 913 .

14. Kekwick, R. A. 1940. The serum proteins in multiple myelomatosis. Biochem. J. $34: 1248$.

15. Lalezari, P., and G. E. Bernard. 1965. Identification of a specific leukocyte antigen: another presumed example of $5^{\text {b }}$. Transfusion (Philadelphia). 5: 135.

16. Lalezari, P., B. Thalenfeld, and W. J. Weinstein. 1970. The Third Neutrophile Antigen in Histocompatibility Testing. Munksgaard, Copenhagen. 319. 